\title{
Long-Term Outcome of Angioplasty or Stent Placement for Stenosis of the Cavernous or Petrous Portion of the Internal Carotid Artery
}

\author{
Koichi ITO, ${ }^{1}$ Yutaka KAI, ${ }^{2,3}$ Akio HYODO, ${ }^{4}$ and Shogo ISHIUCHI ${ }^{5}$ \\ ${ }^{1}$ Department of Neurosurgery, Chubu Tokushukai Hospital, Okinawa, Okinawa; \\ Departments of ${ }^{2}$ Cerebrovascular Disease and Acute Coronary Syndrome, and \\ ${ }^{3}$ Neurosurgery, Graduate School of Medical Sciences, \\ Kumamoto University, Kumamoto, Kumamoto; \\ ${ }^{4}$ Department of Neurosurgery, Koshigaya Hospital, \\ Dokkyo Medical University, Koshigaya, Saitama; \\ ${ }^{5}$ Department of Neurosurgery, Faculty of Medicine, \\ University of the Ryukyus, Nakagami, Okinawa
}

\begin{abstract}
Percutaneous transluminal angioplasty (PTA) and stent placement are effective in patients with stenosis of the cavernous or petrous portion of the internal carotid artery (ICA), but the long-term outcomes remain unclear. The present study evaluated long-term outcomes in 54 patients treated by PTA or stent placement for stenotic lesions involving more than $50 \%$ of the cavernous or petrous portion of the ICA with ischemic symptoms or without ischemic symptoms if cerebral blood flow on single photon emission computed tomography images was decreased by $20 \%$ compared with the contralateral side. Followup magnetic resonance, three-dimensional computed tomography, and conventional angiography were performed. Patient condition in the follow-up period was investigated using telephone interviews or questionnaires. PTA was used to treat 13 lesions and stent placement for 41 lesions. Permanent and transient complications occurred in 2 and 5 patients, respectively. The morbidity rate was $13 \%$ (7 of 54 patients). The follow-up period ranged from 3 to 80 months (mean 29.9 months), and restenosis and occlusion were recognized in 4 patients $(7.4 \%)$. Five patients died ( 2 of malignancy and 3 of myocardial infarction) during the follow-up period. PTA and stent placement are safe and effective in patients with stenosis of the cavernous or petrous portion of the ICA, and result in low long-term rates of restenosis.
\end{abstract}

Key words: internal carotid artery, arterial stenosis, stenting, percutaneous transluminal angioplasty, three-dimensional computed tomography angiography

\section{Introduction}

Intracranial atherosclerotic stenosis may result in cerebral infarction due to perfusion disturbance or artery-to-artery embolization. ${ }^{13)}$ Patients with arteryto-artery embolization tend to have a poor prognosis. Of all cerebral infarcts, $8-10 \%$ are attributable to intracranial atherosclerotic stenosis that can be treated effectively with antiplatelet drug therapy. ${ }^{3,12)}$ Although aspirin is a widely-used antiplatelet drug that reduces the incidence of brain ischemia by about $20 \%,{ }^{2)}$ only aspirin administration cannot prevent cerebral infarction.

Received May 31, 2011; Accepted September 12, 2011
Percutaneous transluminal angioplasty (PTA) for intracranial stenotic disease was introduced in the $1980 \mathrm{~s},{ }^{14)}$ followed by combined stent placement in the 1990s. ${ }^{8,22)}$ PTA is used to treat stenotic lesions of the intracranial artery, but is associated with complications such as elastic recoil, acute obstruction, plaque embolization, arterial dissection, and occlusion of the perforating artery. ${ }^{17,20)}$ Some of these complications may also occur after stent placement. ${ }^{8,10,18,20,22)}$ The effectiveness of intracranial stenting was first confirmed in patients who underwent vertebrobasilar artery stenting. ${ }^{8,10,22)}$ As the vertebrobasilar artery can be approached directly from the femoral artery, navigation in this vessel is easier than in the internal carotid artery (ICA) system with tortuous cavernous and petrous portions. 
Moreover, as the cavernous and petrous portions of the ICA are surrounded by the cavernous sinus or cranial skull base, the balloon-mounted stent system is difficult to navigate. Stents have been placed in the cavernous or petrous portion of the ICA, but long-term follow-up findings and results in large numbers of patients have not yet been reported. ${ }^{20)}$

The present long-term follow-up study of 54 patients with stenotic lesions in the cavernous or petrous portion of the ICA treated by PTA or stent placement assessed the success, morbidity, and mortality rates, the incidence of post-treatment cerebrovascular disease, the post-treatment rate of restenosis, and the long-term treatment outcomes.

\section{Materials and Methods}

A total of 156 patients with intracranial artery stenosis underwent angiography at our institution between April 2000 and March 2009. The neuroradiological images were obtained by magnetic resonance (MR), three-dimensional computed tomography (3D$\mathrm{CT}$ ), and conventional angiography studies. Using criteria developed by the North American Symptomatic Carotid Endarterectomy Trial group, ${ }^{15)}$ we calculated the stenosis rate on MR/3D-CT angiograms to compare the diameter of the vessel at the site of greatest narrowing with the diameter of a normal artery distal to the lesion.

During this period, 54 patients, 43 men and 11 women aged from 51 to 78 years (mean 66.8 years), were treated for stenosis involving more than $50 \%$ of the cavernous (13 patients) or petrous (41 patients) portion of the ICA. Of the 54 patients, 32 were asymptomatic and 22 were symptomatic; 5 presented with transient ischemic attacks, 12 with cerebral infarction, and 5 with amaurosis. Asymptomatic patients $(\mathrm{n}=32)$ with stenosis exceeding $50 \%$ were also treated if cerebral blood flow (CBF) was decreased by $20 \%$ on single photon emission computed tomography (SPECT) images compared to the contralateral side.

All patients received aspirin before treatment, and ticlopidine or cilostazol (dual antiplatelet therapy) was additionally administered for at least 7 days before treatment. All procedures were performed under local anesthesia. All patients underwent angiography before the procedures to evaluate the stenotic ratio and to develop the appropriate treatment strategy. The patients received an intravenous bolus of $5000 \mathrm{U}$ of heparin just before and an intravenous infusion of $500-1000 \mathrm{U} / \mathrm{hr}$ during the procedure to achieve activated clotting time of more than 300 seconds.

Stent placement was first attempted, but if difficult, PTA was performed. All stents were the balloon-expandable type used for coronary stenting as follows: S-670® (Medtronic Vascular, Santa Rosa, California, USA), TSUNAMI ${ }^{\circledR}$ (Terumo, Tokyo), Duraflex ${ }^{\circledR}$ (Avantec Vascular, Sunnyvale, California, USA), Tristar ${ }^{\circledR}$ (Guidant, St. Paul, Minnesota, USA), and Driver ${ }^{\circledR}$ (Medtronic Vascular) instrumentation; and Penta ${ }^{\circledR}$ (Guidant), Radius ${ }^{\circledR}$ (Boston Scientific, San Diego, California, USA), Gateway ${ }^{\circledR}$ (Boston Scientific), and Stormer ${ }^{\circledR}$ (Medtronic Vascular) balloons.

Post-treatment, all patients received heparin (6000-10000 IU per day) or argatroban (60 mg per day) for 2 days. Patients without neurological deficits and without areas of abnormal intensity on MR imaging were identified; dual antiplatelet therapy was continued for 3 months after treatment. Followup MR and 3D-CT angiography was performed at 3 months post-treatment. If no restenosis was recognized, the treatment was changed to single antiplatelet therapy. If restenosis was suspected, conventional angiography was performed and the PTA procedure was repeated if the stenotic lesion involved more than $70 \%$ of the vessel, even if the patient was asymptomatic. If the stenotic lesion affected less than $70 \%$ of the vessel, the patient continued to receive dual antiplatelet therapy until the next evaluation. Thereafter, MR or 3D-CT angiography was performed 6 and 12 months later. If restenosis was suspected, the earlier procedure was repeated. In patients with no evidence of restenosis, only aspirin

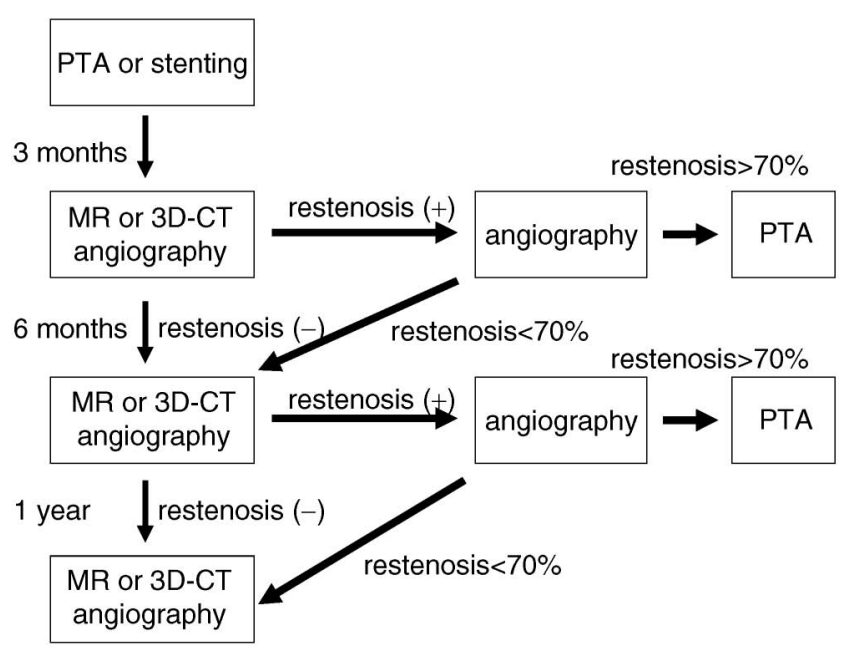

Fig. 1 Algorithm for follow-up examination after percutaneous transluminal angioplasty (PTA) or stent placement in patients with stenosis of the cavernous or petrous portion of the internal carotid artery. 3D-CT: three-dimensional computed tomography, MR: magnetic resonance. 
Table 1 Summary of patients with post-treatment complications

\begin{tabular}{|c|c|c|c|c|c|}
\hline Case No. & Age (years)/Sex & Lesion & Treatment (device) & Complication & Symptom \\
\hline 1 & $74 / \mathrm{F}$ & petrous portion & stent (Driver) & distal embolism & motor weakness \\
\hline \multicolumn{6}{|c|}{ Transient complication: } \\
\hline 3 & $62 / \mathrm{M}$ & petrous portion & stent (Driver) & distal embolism & motor weakness \\
\hline 4 & $56 / F$ & petrous portion & stent (Driver) & distal embolism & motor weakness \\
\hline 7 & $72 / \mathrm{M}$ & cavernous portion & PTA (Gateway) & cortical hematoma & none \\
\hline
\end{tabular}

F: female, M: male, PTA: percutaneous transluminal angioplasty.

Table 2 Summary of patients with re-treatment for re-stenosis

\begin{tabular}{|c|c|c|c|c|c|c|c|c|c|}
\hline \multirow{2}{*}{$\begin{array}{l}\text { Case } \\
\text { No. }\end{array}$} & \multirow{2}{*}{$\begin{array}{c}\text { Age } \\
\text { (year)/ } \\
\text { Sex }\end{array}$} & \multirow[b]{2}{*}{ Lesion } & \multicolumn{3}{|c|}{ Stenotic ratio (\%) } & \multirow{2}{*}{$\begin{array}{c}\text { Treatment } \\
\text { (device) }\end{array}$} & \multirow{2}{*}{$\begin{array}{l}\text { Medication in } \\
\text { follow up }\end{array}$} & \multirow{2}{*}{$\begin{array}{c}\text { Additional } \\
\text { treatment }\end{array}$} & \multirow{2}{*}{$\begin{array}{l}\text { Timing of } \\
\text { re-treatment } \\
\text { (months) }\end{array}$} \\
\hline & & & $\begin{array}{l}\text { Pre- } \\
\text { treatment }\end{array}$ & $\begin{array}{l}\text { Post- } \\
\text { treatment }\end{array}$ & $\begin{array}{l}\text { Follow } \\
\text { up }\end{array}$ & & & & \\
\hline 8 & $77 / \mathrm{M}$ & $\begin{array}{l}\text { petrous } \\
\text { portion }\end{array}$ & 50 & 40 & 75 & stent (Driver) & aspirin, ticlopidine & PTA & 12 \\
\hline 9 & $64 / \mathrm{M}$ & $\begin{array}{l}\text { petrous } \\
\text { portion }\end{array}$ & 64 & 10 & 70 & stent (Driver) & aspirin, ticlopidine & PTA & 7 \\
\hline
\end{tabular}

F: female, M: male, PTA: percutaneous transluminal angioplasty.

treatment was continued (Fig. 1). We recorded the post-treatment status of all patients based on questionnaires or telephone interviews conducted in March 2009.

\section{Results}

Of the 54 patients, 13 underwent PTA (cavernous portion in 3 cases, petrous portion in 10 cases) and 41 were treated by stent placement (cavernous portion in 10 cases, petrous portion in 31 cases). The mean stenosis ratio at the cavernous portion of the ICA decreased from $70.2 \%$ to $3.3 \%$ after stenting and from $77.5 \%$ to $1.5 \%$ after PTA. The mean stenosis ratio at the petrous portion of the ICA decreased from $68.6 \%$ to $6.7 \%$ after stent placement and from $66.7 \%$ to $16.7 \%$ after PTA. The improvement ratio of ICA stenosis was lower at the petrous than the cavernous portion. However, there was no significant difference between the patient groups.

Permanent complications occurred in 2 patients; one patient had hemiparesis and aphasia due to distal embolism, and the other suffered extravasation due to guidewire penetration. In a patient with posttreatment consciousness disturbance, CT showed subarachnoid hemorrhage (SAH). Transient complications were observed in 5 patients, 4 had transient hemiparesis due to distal embolism, and one developed a small cortical hematoma without neurological symptoms (Table 1). The overall morbidity rate was $13 \%$ (7 of 54 patients).

No patient exhibited ischemic symptoms after PTA or stent placement during the follow-up periods ranging from 3 to 80 months (mean 29.9 months). Four repeat PTA procedures were performed for restenosis in the follow-up period. The interval to re-treatment was 6-14 months (mean 9.75 months) (Table 2). None of these 4 patients experienced complications. Five patients died, 2 of cancer and 3 of acute myocardial or cerebral infarction on the contralateral side and cerebral hemorrhage.

\section{Representative Case}

A 62-year-old man with a history of diabetes mellitus and hypertension (Case 3) was incidentally found to have severe stenosis ( $80 \%)$ of the left petrous portion of the ICA (Fig. 2A). Although he was asymptomatic, we suspected $\mathrm{CBF}$ reduction in the left cerebral 

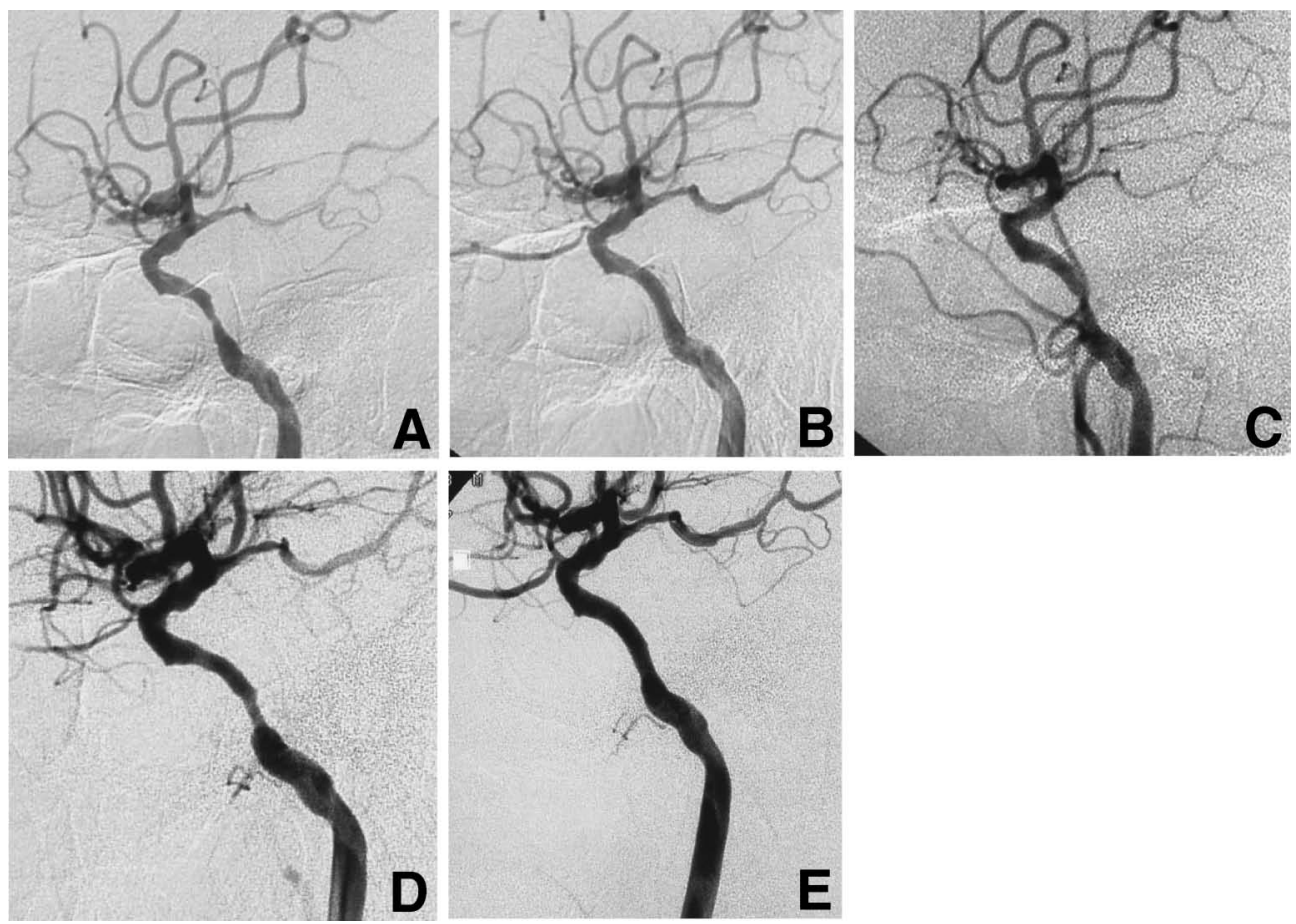

Fig. 2 Case 3. Left internal carotid angiograms (lateral view) showing severe stenosis (about $80 \%$ ) at the petrous portion of the left internal carotid artery (A), almost complete normalization of the stenotic lesion immediately after stent placement (B), mild restenosis at the stent site 3 months after stenting (C), progression of the restenotic lesion after 6 months (D), and the re-treated site is stable after 2 years (E).

hemisphere based on SPECT findings. The stenosis at the left petrous portion of the left ICA was treated using a Driver stent $(4 \times 9 \mathrm{~mm})$. Control angiography performed at the end of the procedure demonstrated almost complete dilation of the stenotic lesion (Fig. 2B). Post-treatment, he developed transient hemiparesis that disappeared after several weeks. Dual antiplatelet therapy was continued and he was discharged home in satisfactory condition.

He had no neurological deficits at the 3-month follow-up examination. Control 3D-CT angiography confirmed that the stent graft was in the correct position, and suggested mild restenosis of the left ICA, but the stenotic ratio was under $70 \%$ (Fig. $2 \mathrm{C}$ ) so we continued conservative treatment with dual antiplatelet therapy. He had no neurological deficits at the 6-month follow-up examination. Angiography confirmed progression of the restenotic lesion in the petrous portion of the left ICA (Fig. 2D) and he underwent PTA. Angiography obtained 2 years later revealed no evidence of restenosis (Fig. $2 \mathrm{E}$ ) and his subsequent course was uneventful.

\section{Discussion}

The present study demonstrated that at a mean fol- low-up of 29.9 months, 48 (88.9\%) of our 54 patients had an excellent outcome. The morbidity rate was $13 \%$ and 4 patients $(7.4 \%)$ required re-treatment after PTA after a mean interval of 9.75 months; none of these patients suffered complications after retreatment. Approximately $10 \%$ of our patients experienced complications after the initial PTA/stent treatment for intracranial stenotic disease; this complication rate agrees with earlier reports. $6,14,17,18,20)$ An important factor underlying the development of complications was distal embolism during the procedures. Our long-term outcomes were satisfactory and, compared to others, ${ }^{1,4,10)}$ the re-stenosis rate in our series was low.

The mean stenosis ratio at the cavernous portion of the ICA decreased from $70.2 \%$ to $3.3 \%$ after stent placement, and from $77.5 \%$ to $1.5 \%$ after PTA. The mean stenosis ratio at the petrous portion of the ICA decreased from $68.6 \%$ to $6.7 \%$ after stenting, and from $66.7 \%$ to $16.7 \%$ after PTA. However, there was no significant difference between the patient groups, although the improvement ratio of ICA stenosis was lower at the petrous than the cavernous portion, and lower after PTA than stenting. All retreated patients underwent PTA of the petrous portion of the ICA. Therefore, we suspect that the 
poor improvement ratio of ICA stenosis at the petrous portion after the first PTA procedure contributed to the occurrence of restenosis. Only PTA cannot achieve full dilation of petrous lesions because of the surrounding petrous bone. PTA lowered the incidence of restenosis, ${ }^{18)}$ but elastic recoil and vessel dissection occurred if over-sized PTA balloons were used.6,21)

Technological advances have facilitated the approach to cerebral vessels, and intravascular treatment using balloons and stents has become increasingly safe and effective. All stents we used were of the balloon-expandable type, because the use of selfexpandable stents has not yet been approved in Japan. Balloon-expandable stents are rigid, so are difficult to place in the tortuous cavernous or petrous portion of the ICA. The new generation of intracranial stents, e.g. self-expandable and drug-eluting stents such as Wingspan (Boston Scientific), ${ }^{5)}$ Neuroform (Boston Scientific), ${ }^{19)}$ and Apollo stents (MicroPort Medical [Shanghai], Shanghai, PRC), ${ }^{11)}$ may be safer and more useful. Drug-eluting stents effectively prevented restenosis during a mean followup period of 14.3 months. ${ }^{16)}$ These stents may reduce intra-procedural risks and lower the rate of restenosis. ${ }^{5,11,16,19)}$

We detected restenosis in the course of follow-up MR and 3D-CT angiography studies. However, MR angiography after stent placement failed to show arterial flow. Therefore, the correct evaluation of restenosis after PTA requires imaging by both methods. Nonetheless, we found restenosis difficult to detect after stent placement because the stent material produces artifacts. Angiography is the best technique for the detection of restenosis after stent placement, but may elicit complications and is not useful for repeated examinations in the course of long-term follow up. ${ }^{7)}$ Quantitative MR angiography using the phase-contrast MR technique ${ }^{1)}$ or multislice $\mathrm{CT}^{4,9)}$ studies can help to identify in-stent stenosis. These neuroradiological examinations are a suitable noninvasive alternative to conventional angiography, but have limited value in the evaluation of stenosis in small vessels treated by stenting.

The present study showed that PTA and stent placement are safe and effective methods to treat patients with stenosis of the cavernous or petrous portion of the ICA that yield satisfactory long-term outcomes. However, there are some limitations. Our study was retrospective, not all patients received full medication therapy before PTA or stent placement, and the data were collected from a single center. Therefore, we cannot rule out selection bias. We are planning to carry out a prospective multicenter randomized control study in patients treated for steno- sis of the cavernous or petrous portion of the ICA.

\section{References}

1) Amin-Hanjani $S$, Alaraj A, Calderon-Arnulphi $M$, Aletich VA, Thulborn KR, Charbel FT: Detection of intracranial in-stent restenosis using quantitative magnetic resonance angiography. Stroke 41: 2534-2538, 2010

2) Bose A, Hartmann M, Henkes H, Liu HM, Teng MM, Szikora I, Berlis A, Reul J, Yu SC, Forsting M, Lui M, Lim W, Sit SP: A novel, self-expanding, nitinol stent in medically refractory intracranial atherosclerotic stenoses: The Wingspan study. Stroke 38: 1531-1537, 2007

3) Chimowitz MI, Lynn MJ, Howlett-Smith H, Stern BJ, Hertzberg VS, Frankel MR, Levine SR, Chaturvedi S, Kasner SE, Benesch CG, Sila CA, Jovin TG, Romano JG: Comparison of warfarin and aspirin for symptomatic intracranial arterial stenosis. $N$ Engl J Med 352: 1305-1316, 2005

4) Choo KS, Lee TH, Choi CH, Park KP, Kim CW, Kim S: Assessment of the intracranial stents patency and re-stenosis by 16-slice CT angiography with optimized sharp kernel: Preliminary study. J Korean Neurosurg Soc 45: 284-288, 2009

5) Collaborative overview of randomised trials of antiplatelet therapy-I: Prevention of death, myocardial infarction, and stroke by prolonged antiplatelet therapy in various categories of patients. Antiplatelet Trialists' Collaboration. BMJ 308: 81-106, 1994

6) Connors JJ 3rd, Wojak JC: Percutaneous transluminal angioplasty for intracranial atherosclerotic lesions: Evolution of technique and short-term results. J Neurosurg 91: 415-423, 1999

7) Dawkins AA, Evans AL, Wattam J, Romanowski CA, Connolly DJ, Hodgson TJ, Coley SC: Complications of cerebral angiography: A prospective analysis of 2,924 consecutive procedures. Neuroradiology 49: 753-759, 2007

8) Fiorella D, Chow MM, Anderson M, Woo H, Rasmussen PA, Masaryk TJ: A 7-year experience with balloon-mounted coronary stents for the treatment of symptomatic vertebrobasilar intracranial atheromatous disease. Neurosurgery 61: 236-243, 2007

9) Hahnel S, Trossbach M, Braun C, Heiland S, Knauth M, Sartor K, Hartmann M: Small-vessel stents for intracranial angioplasty: In vitro comparison of different stent designs and sizes by using CT angiography. AJNR Am J Neuroradiol 24: 1512-1516, 2003

10) Jiang WJ, Xu XT, Du B, Dong KH, Jin M, Wang QH, Ma N: Long-term outcome of elective stenting for symptomatic intracranial vertebrobasilar stenosis. Neurology 68: 856-858, 2007

11) Jiang WJ, Xu XT, Jin M, Du B, Dong KH, Dai JP: Apollo stent for symptomatic atherosclerotic intracranial stenosis: Study results. AJNR Am J Neuroradiol 28: 830-834, 2007

12) Kasner SE, Lynn MJ, Chimowitz MI, Frankel MR, 
Howlett-Smith H, Hertzberg VS, Chaturvedi S, Levine SR, Stern BJ, Benesch CG, Jovin TG, Sila CA, Romano JG: Warfarin vs aspirin for symptomatic intracranial stenosis: Subgroup analyses from WASID. Neurology 67: 1275-1278, 2006

13) Li H, Wong KS: Racial distribution of intracranial and extracranial atherosclerosis. J Clin Neurosci 10: 30-34, 2003

14) Marks MP, Wojak JC, Al-Ali F, Jayaraman M, Marcellus ML, Connors JJ, Do HM: Angioplasty for symptomatic intracranial stenosis: Clinical outcome. Stroke 37: 1016-1020, 2006

15) North American Symptomatic Carotid Endarterectomy Trial Collaborators: Bene?cial effect of carotid endarterectomy in symptomatic patients with highgrade carotid stenosis. N Engl J Med 325: 445-453, 1991

16) Qureshi AI, Kirmani JF, Hussein HM, Harris-Lane P, Divani AA, Suri MF, Janjua N, Alkawi A: Early and intermediate-term outcomes with drug-eluting stents in high-risk patients with symptomatic intracranial stenosis. Neurosurgery 59: 1044-1051, 2006

17) Rostomily RC, Mayberg MR, Eskridge JM, Goodkin R, Winn HR: Resolution of petrous internal carotid artery stenosis after transluminal angioplasty. Case report. J Neurosurg 76: 520-523, 1992

18) Terada $T$, Tsuura $M$, Matsumoto $H$, Masuo $O$, Tsumoto T, Yamaga H, Itakura T: Endovascular therapy for stenosis of the petrous or cavernous portion of the internal carotid artery: Percutaneous transluminal angioplasty compared with stent placement. J Neurosurg 98: 491-497, 2003

19) Turk AS, Ahmed A, Niemann DB, Aagaard-Kienitz B, Brooks N, Levine RL: Utilization of self-expanding stents in the treatment of intracranial atherosclerotic disease in the distal small cerebral vessels. Neuroradiology 49: 659-663, 2007

20) Wojak JC, Dunlap DC, Hargrave KR, DeAlvare LA, Culbertson HS, Connors JJ 3rd: Intracranial angioplasty and stenting: Long-term results from a single center. AJNR Am J Neuroradiol 27: 1882-1892, 2006

21) Yadav JS, Roubin GS, Iyer S, Vitek J, King P, Jordan WD, Fisher WS: Elective stenting of the extracranial carotid arteries. Circulation 95: 376-381, 1997

22) Yu W, Smith WS, Singh V, Ko NU, Cullen SP, Dowd CF, Halbach VV, Higashida RT: Long-term outcome of endovascular stenting for symptomatic basilar artery stenosis. Neurology 64: 1055-1057, 2005

Address reprint requests to: Yutaka Kai, MD, PhD, Department of Cerebrovascular Disease and Acute Coronary Syndrome, Graduate School of Medical Sciences, Kumamoto University, 1-1-1 Honjo, Kumamoto 860-8556, Japan.

e-mail: ykai@fc.kuh.kumamoto-u.ac.jp 